\title{
The Impact of Implementing Electronic Workforce Management System in Hamad Medical Corporation on Nursing Staff Management
}

\author{
Noha Ahmed and Wasmiya Dalhem* \\ Department of Nursing Informatics, Hamad Medical Corporation, Doha, Qatar
}

*Corresponding author: Wasmiya Dalhem, Department of Nursing Informatics, Hamad Medical Corporation, Doha, Qatar, E-mail: NAHMED10@hamad.qa

Received: 30 Sep, 2019 | Accepted: 29 Oct, 2019 | Published: 08 Nov, 2019

Citation: Ahmed N, Dalhem W (2019) The Impact of Implementing Electronic Workforce Management System in Hamad Medical Corporation on Nursing Staff Management. J Epidemiol Public Health Rev 4(3): dx.doi.org/10.16966/2471-8211.175

Copyright: (C) 2019 Ahmed N, et al. This is an open-access article distributed under the terms of the Creative Commons Attribution License, which permits unrestricted use, distribution, and reproduction in any medium, provided the original author and source are credited.

\begin{abstract}
Despite of the benefits of implementing an integrated workforce management system in healthcare setting, having a system capable of processing staff data, facilitating patient assignment according to acuity level and the nursing workload, there is no enough evidenced based data on the improvements and gains of the transformation from previous staffing practices to a comprehensive workforce Management system. The purpose of this study is to assess impact of implementing the Work force Management System in enhancing the effectiveness of staffing management and the level of end user satisfaction compared to the previous workflow. A quantitative study design was adopted where a questionnaire survey was conducted with 113 nursing managers and 231 staff nurses who approved to participate in the research. The survey tools were divided to two parts; part1 to survey nursing managers and part 2 to survey the staff nurses. Findings revealed that automating staffing management has positive impact on the nurses manager staffing management practice as $80.5 \%$ agreed on the effectiveness of workforce management system and $74.9 \%$ of staff nurses are generally satisfied with the system. In conclusion, the Interoperability of workforce management system may result in higher satisfaction rate but it increases the need for continuous training and familiarization in addition to close system monitoring and optimization. Thus, in order to achieve effective scheduling, optimal utilization of staffing, and fair distribution of assignments with consideration of patient acuity level, it is recommended to develop a competency based training framework in order to improve using the system by end users as required in addition developing workforce system performance optimization plan to ensure the system is effectively performing.
\end{abstract}

Keywords: Nurse administrators; Workload; Nursing informatics decision making

\section{Introduction}

Technological solutions are tools through which philosophy, policies and practices are reflected and operationalized. In this line, it is used in nursing to help manage the complex world of delivering patient care. Nurse Managers rely on these solutions to improve their abilities in assuring that the right resources are assigned to the right situations which result to high quality, safety and profitable financial outcomes [1-4]. Thus, it is important to gain a deeper perspective around many operational, financial implications and opportunities associated with staffing and scheduling which would assist improving the efficiency and effectiveness of scheduling activities, promoting participation, choice and fairness among staff [5-8].

In this respect, Hamad Medical Corporation (HMC) is the first multi facility in the Middle East to implement a new electronic workforce management system Cerner Clairvia for managing over 9,000 nursing staff. The Nursing Informatics Department is leading the system implementation through the eight hospitals. The new electronic system (Cerner Clairvia) consists of a group of modules which are: 1. Demand Manager continuously tracks and predicts patients' clinical status so the right number and type of caregivers are accurately associated to patient demand. 2. Outcomes-Driven Acuity solution bases staffing levels on desired patient outcomes. 3. Patient Assignment solution ensures that the right number and competent caregiver are assigned to the patient, bringing patient-focused staffing to its highest level. Staff Manager Solution provides a single staffing viewpoint in real-time for the most effective timely staffing decisions. 5. Patient Progress Manager monitors patient progress against established benchmarks to determine if patients are following expected progress plans for hospital discharge. The previous practice was managing staffing and assignments on Microsoft excel sheet. All staff requests were managed manually, and their time and labor aspects were managed through separate legacy system which created workloads on the nursing managers. With the transformation to electronic workforce management system nursing managers are able to create staff patterns and trends, assign staff according to patient need and level of acuity, manage shortage, overtime according to projected units' demand and extracting around 150 reports which assist in evidence based decision making. Moreover, Staff Nurses (SN) are able to communicate their requests of duty and 
shift swaps through the system. The workforce management system is integrated with the finance management system in order to save time and effort.

Despite of the stated benefits from the system there is no enough evidenced based data on the improvements and gains from the transformation to previous staffing practices to a comprehensive workforce Management system. Thus, Nursing Informatics department is conducting this research to assess impact of implementing the Work force Management System in enhancing the staffing management compared to the previous workflow, facilitating patient assignment according to acuity level and the nursing workload and increasing work satisfaction.

\section{Objective of the Study}

\section{Primary}

To assess The Impact of implementing Electronic Workforce Management System in Hamad Medical Corporation on staff Management Practice.

\section{Secondary}

- To identify the factors affecting the utilization of the Workforce Management system.

- To measure the end users satisfaction toward the utilization of the Work force Management System in Hamad Medical Corporation.

\section{Methodology}

\section{Design}

A quantitative study design was adopted for the present study due to the nature of the research objectives where a questionnaire survey was conducted with the targeted sample.

\section{Instrument}

The researcher developed two questionnaire survey instruments:

Instrument 1 was targeting the nursing managers (For: Executive Director of Nursing (EDON), Director of Nursing (DON), Nursing House Supervisors (HNS), Head Nurses (HN), Charges Nurses (CN), utilizing the system for scheduling, assigning the right nurse to the right patient, extracting reports related to staffing and productivity. It consisted of 24 questions categorized under five sections: section 1 general information, section 2 staffing workflow, section 3 system utilization, compliance and data quality, section 4 effectiveness and efficiency of implementing the system and section 5 nurse managers satisfaction.

Instrument 2 was targeting Staff Nurses (SN) from all units working in 6 hospitals that implemented the workforce management system, were they utilize it in viewing their schedules, and requesting for shifts swaps with their colleagues or special duty request, in addition to viewing their patient's assignments. The questionnaire had two sections: section 1 included general information, and section 2 included statements denoting staff satisfaction with the system functionalities on a 5 points Likert scale where 5 denotes strongly agree, $4=$ agree, $3=$ neutral, $2=$ disagree and $1=$ strongly disagree.

Both instruments were content validated by experts in the field of Nursing Informatics and Information Technology to ascertain its relevance, piloted and accordingly modified. No further statistics analysis was done for the pilot study results which could be considered a limitation of the study.

\section{Sample}

Purposive sampling was used to recruit 844 targeted staff utilizing the electronic workforce management system.

Inclusion criteria: Executive Director of Nursing (EDON), Director of Nursing (DON), Nursing House Supervisors (HNS), Head Nurses (HN), Charges Nurses (CN) (Tool 1) and Staff Nurses (SN) from all units that in six facilities that implemented Clairvia where surveyed by (Tool 1). In addition to Staff nurses were included in the satisfaction survey only (Tool 2).

Exclusion criteria: Staff nurses and nurse managers working in medical department not reporting to nursing administration, staff nurses and nurse managers in facility has implemented workforce management system less than 6 months at the time of the study, any hospital under renovation, demolishing, transferring of some units, and staff nurses were included only in the satisfaction survey (tool 2).

\section{Setting}

All Hamad Medical Corporation Facilities that implemented the workforce management system for at least 6 months at time of the study were included which are: Alkhor, Women's, Heart, National Cancer Care Center and Research (NCCR), Al wakra Hospital and Cuban Hospital where all Clinical units under nursing department in the previous mentioned facilities were included.

\section{Data collection}

- Official permission was obtained from the Medical Research Department.

- A questionnaire was developed by the researcher after a thorough review of the literature $[5,6,9]$. The survey tools were content validated by experts in the field of Nursing Informatics and Information Technology to ascertain its relevance.

- The Questionnaires were designed on Survey Monkey by Hamad Medical Corporation Web section team; the link for the surveys were distributed via email for all designated participants, where they can respond anonymously. It was clearly communicated in the instrument info sheet that participating in the research is not mandatory, thus answering the questionnaire was considered to be equivalent to informed consent to be included in the study.

- Data collection was done concurrently in all designated facilities within 3 weeks.

\section{Ethical Consideration and Limitation of the Study}

- The researchers abided by the rules and regulation guidelines of the Research Committee of HMC related to intellectual property, conflict of interest, authorship and financial issues.

- The researcher used scientific rigor and integrity in obtaining, recording and analyzing data; and in reporting results according to Good Clinical Practice (GCP) in Hamad Medical Corporation.

- Regardless of the considerably less responses than planned from the nurses, no incentives were given to increase participation in order not to influence their opinion.

- The financial impact of scheduling and utilizing of the resources was subjectively assessed for the manager perception, which will need future investigation based on reports extracted from the system compared to planned budgets. 


\section{Data Analysis}

Data were entered and verified using the SPSS (Statistical Package for Social Science) version 21.0 to perform the tabulation and statistical analysis. Categorical and continuous values were expressed as frequency (percentage) and mean $\pm \mathrm{SD}$. Descriptive statistics were used to summarize all demographic and other characteristics of the participants.

\section{Results}

\section{Descriptive statistics}

Hospital facility: The Surveys were distributed; Survey 1 targeting Nursing Managers who are responsible for staffing and utilizing the full system functionalities and Survey 2 targeting staff nurses who utilize the web functionality of the System in order to request, swap their duty, and view their monthly schedule. As table 1 reveals, out of the 113 respondents who answered first survey, $17.7 \%$ are from Heart Hospital $(\mathrm{N}=20), 7.1 \%$ are from NCCCR $(\mathrm{N}=8), 17.7 \%$ are from Women's hospital $(\mathrm{N}=120), 24.8 \%$ are from Al Wakra Hospital $(\mathrm{N}=28)$, and the highest number of respondents was $26.5 \%$ from the Cuban Hospital $(\mathrm{N}=30)$.

On the other hand, out of the 231 respondents who answered second survey, $15.2 \%$ are from Heart Hospital $(\mathrm{N}=35), 7.8 \%$ are from NCCCR $(\mathrm{N}=18), 23.8 \%$ are from Women's hospital $(\mathrm{N}=55), 9.1 \%$ are from $\mathrm{Al}$ Khor Hospital $(\mathrm{N}=21), 15.6 \%$ are from The Cuban Hospital $(\mathrm{N}=36)$, and the highest number of respondent $28.5 \%$ are from $\mathrm{Al}$ Wakra Hospital $(\mathrm{N}=66)$.

In addition, respondents were asked for how long they have been using the workforce management system to ensure that no respondents are in the orientation period and they are fully aware about the system functionalities and the results suggest that all respondents who participated in nursing manager survey 1 , the majority $87.6 \%$ used the workforce management system for more than 12 months $(\mathrm{N}=99)$ and only $3.5 \%$ used the system for less than 6 months $(\mathrm{N}=4)$. While the majority of nurses who participated in survey $2,87.4 \%$ used the system for more than 12 months $(\mathrm{N}=202)$.

In order to assess the Impact of implementing Electronic Workforce Management System on staff management practice, five main variables were identified: (i) current staffing management workflow, (ii) utilization of the system functionalities, (iii) effectiveness of the system, (iv) accuracy of data provided and (v) the overall nursing manager satisfaction with the workforce management system.

Table 1: Distribution of nurses' managers and staff nurses according to their hospital facility.

\begin{tabular}{|l|c|c|c|c|}
\hline & $\begin{array}{c}\text { Nursing Managers } \\
\text { (Survey 1) }\end{array}$ & $\begin{array}{c}\text { Staff Nurses } \\
\text { (Survey 2) }\end{array}$ & \\
\hline Facility & $\mathbf{f}$ & $\mathbf{\%}$ & $\mathbf{f}$ & $\%$ \\
\hline Heart Hospital & 20 & 17.7 & 35 & 15.2 \\
\hline NCCCR & 8 & 7.1 & 18 & 7.8 \\
\hline Women's Hospital & 20 & 17.7 & 55 & 23.8 \\
\hline Al Khor Hospital & 7 & 6.2 & 21 & 9.1 \\
\hline Al Wakra Hospital & 28 & 24.8 & 66 & 28.5 \\
\hline The Cuban Hospital & 30 & 26.5 & 36 & 15.6 \\
\hline Total & 113 & 100 & 231 & 100 \\
\hline
\end{tabular}

The workforce staff management workflow variables: In comparison between the previous Microsoft excel sheet used for staffing scheduling and current staffing management system. The majority of nursing managers agreed that the system has positively impacted their staffing workflow, in respect to $78 \%$, easier shift requests, $81 \%$, tasks done in timely manner, $78 \%$, efficient distribution of assignments, $84 \%$ provide accurate data and reports and $83 \%$ agreed that the system assisted them in efficient utilization of nursing resources.

The results (Table 2 and Figure 1) show that all the workflow variables had very significant correlations with each other. The highest correlation was between workflow question 5 (The system provides accurate data and reports that may have a greater impact on the quality of patient care delivery compared to the previous system?) and question 6 (The Clairvia system helps in enhancing the utilizing of nursing resources and reduces costs?). There is a significant, positive and strong correlation between providing accurate data and Utilization of Nursing Resources ( $\mathrm{r}(111)=0.796 ; \mathrm{p}<0.01)$. The weakest correlation among all the workflow variable pairs was between question 1 (performance of required tasks on the Clairvia system are done in more timely manner than the previous system) and question 3 (The Clairvia system provides accurate data and reports that may

Table 2: Correlation between current staff management workflow variables.

\begin{tabular}{|c|c|c|c|c|c|c|}
\hline $\begin{array}{c}\text { Satisfaction } \\
\text { with Current } \\
\text { Workflow }\end{array}$ & 1 & 2 & 3 & 4 & 5 & 6 \\
\hline $\begin{array}{l}\text { 1. Easier Shift } \\
\text { Requests }\end{array}$ & 1 & $0.653^{* *}$ & $0.493^{* *}$ & $0.623 * *$ & $0.688 * *$ & $0.659 * *$ \\
\hline $\begin{array}{l}\text { 2. Easier Staff } \\
\text { Assignment }\end{array}$ & & 1 & $0.594 * *$ & $0.629 * *$ & $0.602 * *$ & $0.630 * *$ \\
\hline $\begin{array}{l}\text { 3. Task Done } \\
\text { in Timely } \\
\text { Manner }\end{array}$ & & & 1 & $0.695^{* *}$ & $0.519 * *$ & $0.58 * *$ \\
\hline $\begin{array}{l}\text { 4. Efficient } \\
\text { Distribution }\end{array}$ & & & & 1 & $0.678 * *$ & $0.698 * *$ \\
\hline $\begin{array}{l}\text { 5. Provide } \\
\text { Accurate } \\
\text { Data }\end{array}$ & & & & & 1 & $0.796 * *$ \\
\hline $\begin{array}{l}\text { 6. Utilization } \\
\text { of Nursing } \\
\text { Resources }\end{array}$ & & & & & & 1 \\
\hline
\end{tabular}

Note: ** Correlation is significant at $p<0.01$ level

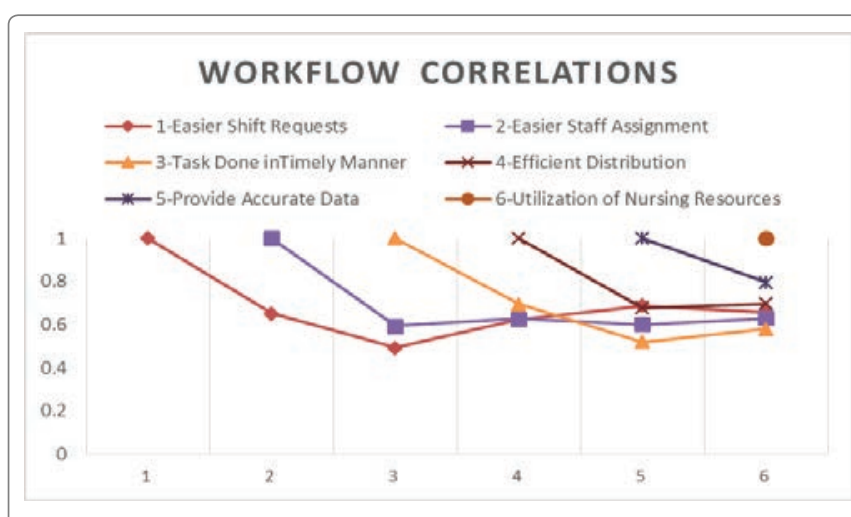

Figure 1: Correlation between current staff management workflow variables.

Citation: Ahmed N, Dalhem W (2019) The Impact of Implementing Electronic Workforce Management System in Hamad Medical Corporation on Nursing Staff Management. J Epidemiol Public Health Rev 4(3): dx.doi.org/10.16966/2471-8211.175 
have a greater impact on the quality of patient care delivery compared to the previous system?). There is a significant, positive and moderate correlation between Easier shift request and Task done in a timely manner $(\mathrm{r}(111)=0.493, \mathrm{p}<0.01)$.

The mean score for workflow variables are in the range of 3.92 to 4.04 which denotes that respondents agree that the new workforce management system is better than the previous workforce management system. The highest mean score is of easier shift requests which shows that respondents agree that the new workforce system has made it easier to manage shift requests $(\mathrm{M}=4.04, \mathrm{SD}=0.74)$ (Figure 2).

The workforce management system utilization variables: In regards to system utilization, $82 \%$ of nurses manager agreed that the data quality of system were valuable in staffing related decision making and budget planning, $78 \%$ agreed on utilizing demand manager module as one of the system tools in providing visibility for analysis on previous staffing decisions and projections against future staffing for recommended adjustments while $80 \%$ agreed upon usefulness scheduling functionalities in the system e.g., patterns, automated requests acceptance, etc., in generating the monthly schedule.

The results in table 3 and figure 3 suggest that all the pairs of utilization variables have significant correlations with each other. The strongest correlation was between question 2 (The data quality of system reports are valuable in staffing related decision making and budget planning?) and question 3 (Demand Manager Screen provides visibility for analysis on previous staffing decisions and projections against future staffing for recommended adjustments?) There is a strong, significant and positive correlation between data quality and demand manager screen $(r(113)=0.792, p<0.01)$. The weakest correlation among all the utilization variables was between question 1 (Scheduling functionalities in the system (e.g. patterns, automated requests acceptance, etc.) are useful in generating the monthly schedule?) and question 4 (The system is helpful in approving or rejecting staff request and shifts swamps?). There is a significant, moderate and positive correlation between useful scheduling and helpful in staff request and shift swamp management $(r(113)=0.502$, $\mathrm{p}<0.01)$.

The utilization variable scores ranged from 3.86 to 3.93 which show high degree of agreement among the respondents that utilization, compliance, and data quality of the Clairvia system is very high indeed. The highest mean is of data quality which shows that respondents believe that the data quality of Clairvia reports are valuable in staffing related decision making and budget planning $(\mathrm{M}=3.93, \mathrm{SD}=0.73)$ (Figure 4).

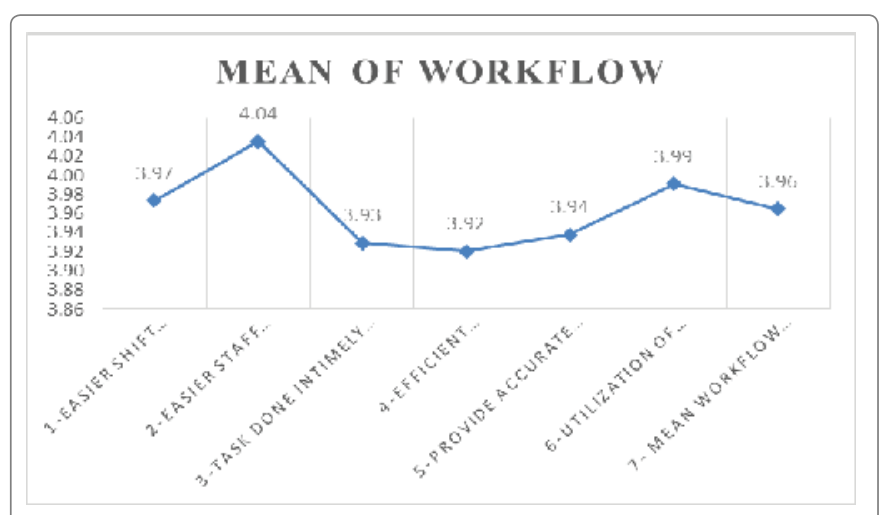

Figure 2: The mean of current staff management workflow variables.
Table 3: Correlation between workforce management system utilization variables.

\begin{tabular}{|l|c|c|c|c|}
\hline \multicolumn{1}{|c|}{ Utilization } & $\mathbf{1}$ & $\mathbf{2}$ & $\mathbf{3}$ & $\mathbf{4}$ \\
\hline 1. Useful Scheduling & 1 & $0.637 * *$ & $0.64 * *$ & $0.502 * *$ \\
\hline 2. Data Quality & & 1 & $0.792 * *$ & $0.659 * *$ \\
\hline 3. Demand Manager Screen & & & 1 & $0.734 * *$ \\
\hline $\begin{array}{l}\text { 4. Helpful in staff request and } \\
\text { shift swamp management }\end{array}$ & & & 1 \\
\hline
\end{tabular}

Note: $* *$ Correlation is significant at $\mathrm{p}<0.01$ level

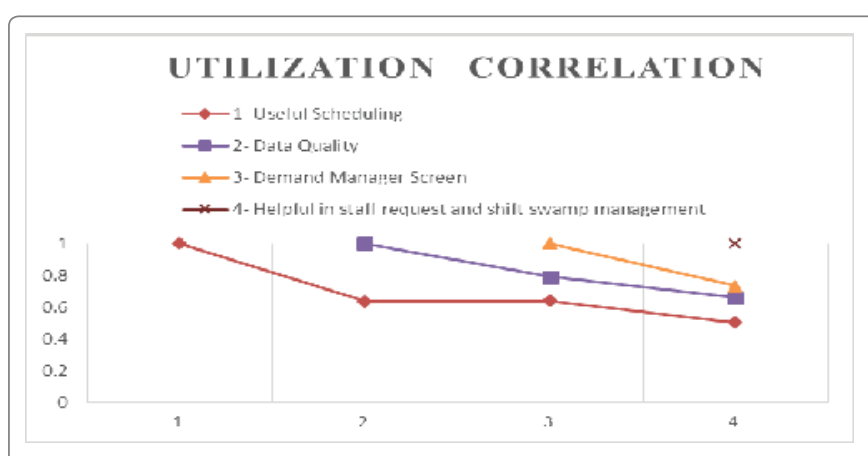

Figure 3: Correlation between workforce management system utilization variables.

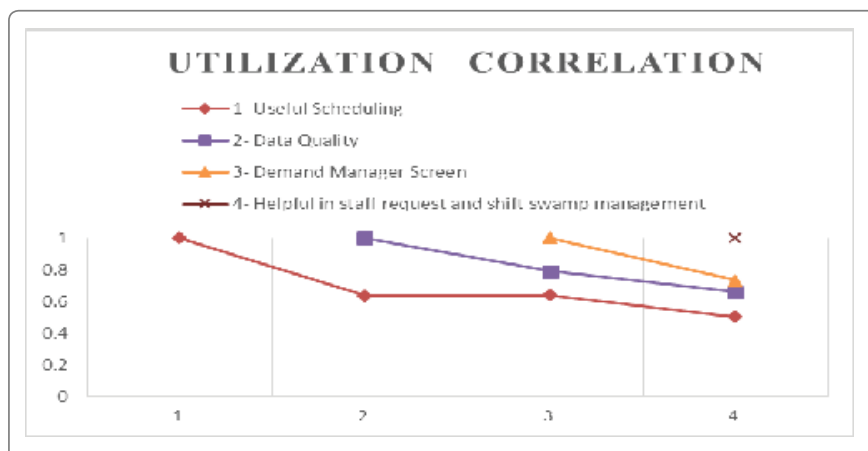

Figure 4: The mean of current staff management workflow variables.

The workforce management system effectiveness variables: In relation to system effectiveness, the majority of nursing managers confirmed that the system is effective in accessing in real time, continuity of care where it allows assigning familiar nurses to their patient, which improves patient care with a rate of $85.8 \%, 81.4 \%$ respectively, while $82.3 \%$ thought the system integration with Oracle Time and Labor (OTL) facilitates easier finalizing and approving of staff timecards and $73.4 \%$ agreed that patient acuity scoring is accurate and reflects the patients' clinical status.

The findings of effectiveness table 4 and figure 5 reveal that there is a strong and significant correlation between all pairs of effectiveness variables and they are significantly correlated with each other. The strongest correlation among all pairs is between question 3 (Using the continuity of care feature in system allows assigning familiar nurses to their patient, which improves patient care?) and question 7 ('Demand Manager' effectively illustrates real time staffing workload based on patient care needs?). There is a significant, positive and very strong correlation between Continuity of Care Feature and Demand Manager Effectiveness $(r(111)=0.837, \mathrm{p}<0.01)$. 


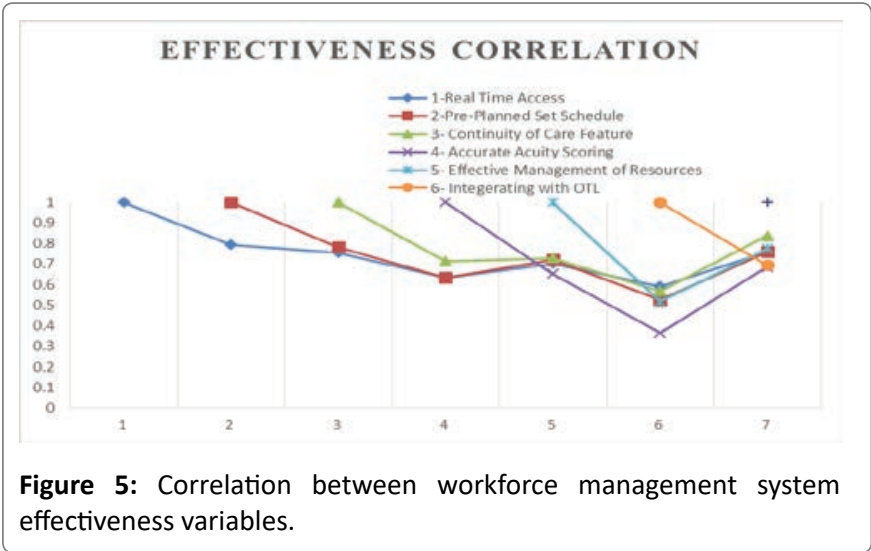

Table 4: Correlation between workforce management system effectiveness variable.

\begin{tabular}{|l|c|c|c|c|c|c|c|}
\hline Efficiency & $\mathbf{1}$ & $\mathbf{2}$ & $\mathbf{3}$ & $\mathbf{4}$ & $\mathbf{5}$ & $\mathbf{6}$ & $\mathbf{7}$ \\
\hline $\begin{array}{l}\text { 1. Real Time } \\
\text { Access }\end{array}$ & 1 & $0.793^{* *}$ & $0.756^{* *}$ & $0.634^{* *}$ & $0.702^{* *}$ & $0.592^{* *}$ & $0.757^{* *}$ \\
\hline $\begin{array}{l}\text { 2. Pre-Planned } \\
\text { Set Schedule }\end{array}$ & 1 & $0.783^{* *}$ & $0.633^{* *}$ & $0.721^{* *}$ & $0.524^{* *}$ & $0.759^{* *}$ \\
\hline $\begin{array}{l}\text { 3. Continuity of } \\
\text { Care Feature }\end{array}$ & 1 & $0.714^{* *}$ & $0.728^{* *}$ & $0.568^{* *}$ & $0.837^{* *}$ \\
\hline $\begin{array}{l}\text { 4. Accurate } \\
\text { Acuity } \\
\text { Scoring }\end{array}$ & 1 & $0.653^{* *}$ & $0.364^{* *}$ & $0.685^{* *}$ \\
\hline $\begin{array}{l}\text { 5. Effective } \\
\text { Management } \\
\text { of Resources }\end{array}$ & & & 1 & $0.517^{* *}$ & $0.774^{* *}$ \\
\hline $\begin{array}{l}\text { 6. Integrating } \\
\text { with OTL }\end{array}$ & & & & & 1 & $0.694^{* *}$ \\
\hline $\begin{array}{l}\text { 7. Demand } \\
\text { Manager } \\
\text { Effectiveness }\end{array}$ & & & & & 1 \\
\hline
\end{tabular}

Note: ${ }^{* *}$ Correlation is significant at $p<0.01$ level

The mean scores of all effectiveness variables range from 3.81 to 4.03 where " 1 " denoted Strongly Disagree and " 5 " denoted "Strongly Agree". The highest mean is of Real Time Access ( $M=4.03, \mathrm{SD}=0.70)$. It indicates that the respondents agree that having real time access to staff schedules on-line is very useful. The grand effectiveness mean also indicates that overall the effectiveness and efficiency of implementing the Clairvia system is very high $(\mathrm{M}=3.94, \mathrm{SD}=0.62)$ (Figure 6).

The workforce management system strengths variables: In regards, the workforce management system strengths variables, the highest rate of agreement among nurses manager were for data accuracy, daily edits of schedule and speed of report generation with $84.9 \%, 85 \%$ and $81.4 \%$ respectively.

The results of the correlation suggest that all the strength variables are strongly correlated with each other at $95 \%$ confidence interval. The strongest correlation among all pairs of strength variables is between ease of scheduling and ease of requesting shifts and swamps $(\mathrm{r}(111)=0.761, \mathrm{p}<0.01)$. The weakest correlation among all the pairs is between data accuracy and ease of report generation $(r(111)=0.484$, $\mathrm{p}<0.01)$ as shown in table 5 and figure 7.

The mean strength variables score range from 3.81 to 4.03 which shows high degree of agreement among the respondents. The highest

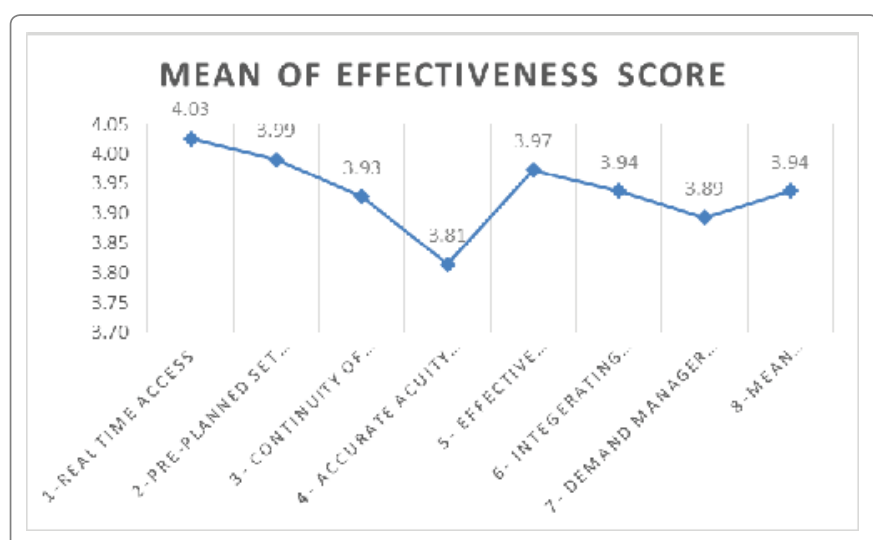

Figure 6: The mean of current staff management workflow variables.
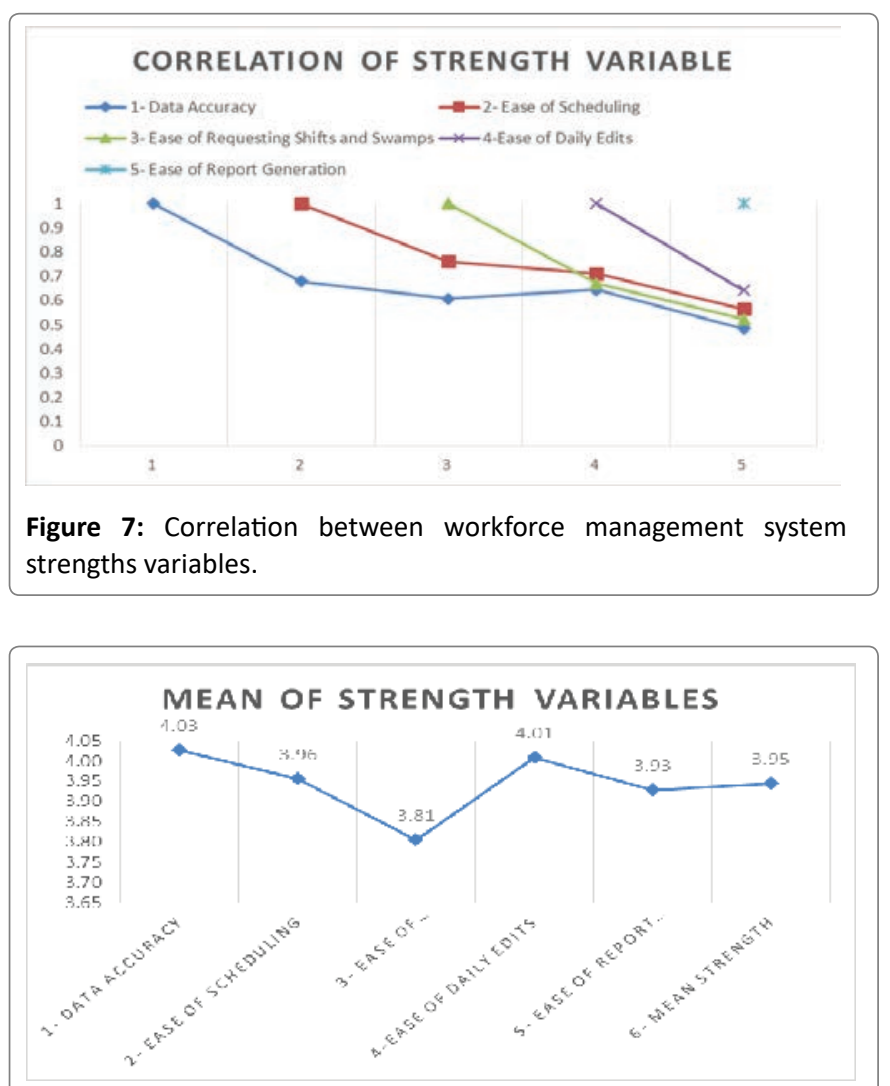

Figure 8: The mean of workforce management system strengths variables.

Table 5: Correlation between workforce management system strengths variables.

\begin{tabular}{|l|c|c|c|c|c|}
\hline \multicolumn{1}{|c|}{ Strengths } & $\mathbf{1}$ & $\mathbf{2}$ & $\mathbf{3}$ & $\mathbf{4}$ & $\mathbf{5}$ \\
\hline 1. Data Accuracy & 1 & $0.680^{* *}$ & $0.608^{* *}$ & $0.644^{* *}$ & $0.484^{* *}$ \\
\hline 2. Ease of Scheduling & & 1 & $0.761^{* *}$ & $0.711^{* *}$ & $0.566^{* *}$ \\
\hline $\begin{array}{l}\text { 3. Ease of Requesting } \\
\text { Shifts and Swamps }\end{array}$ & & 1 & $0.671^{* *}$ & $0.524^{* *}$ \\
\hline 4. Ease of Daily Edits & & & & 1 & $0.642^{* *}$ \\
\hline $\begin{array}{l}\text { 5. Ease of Report } \\
\text { Generation }\end{array}$ & & & & 1 \\
\hline
\end{tabular}

Note: ${ }^{* *}$ Correlation is significant at $\mathrm{p}<0.01$ level 


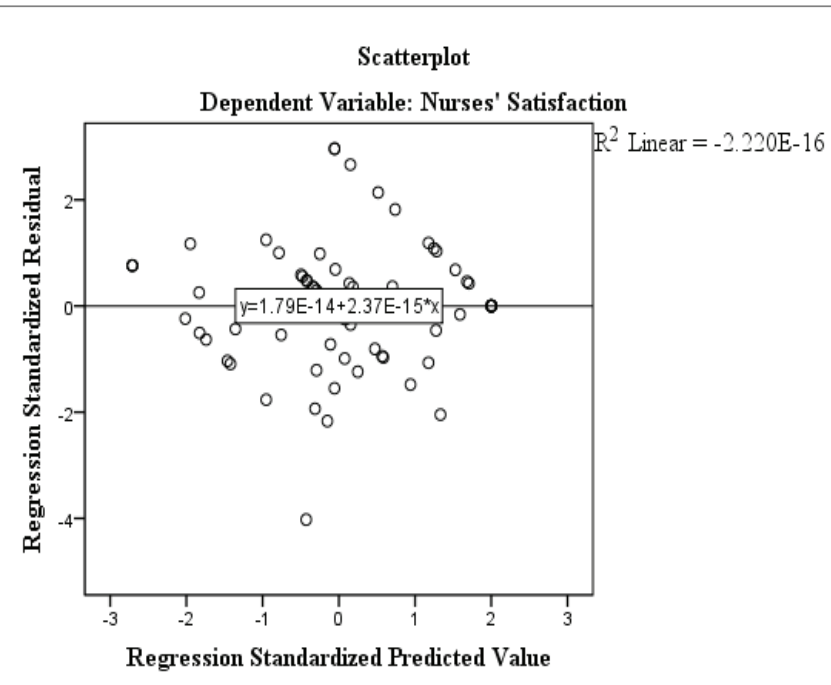

Figure 9: Scatter plot between nurses' satisfaction with Clairvia System and Standardized Residuals.

Table 6: Summary of regression analysis for variables predicting nurses' managers' satisfaction.

\begin{tabular}{|l|c|c|c|c|}
\hline \multicolumn{1}{|c|}{ Satisfaction } & \multicolumn{4}{c|}{ Model 1 } \\
\hline Total Observation & \multicolumn{4}{c|}{113} \\
\hline Included in analysis & \multicolumn{4}{c|}{100} \\
\hline & B & & SE B & $\beta$ \\
\hline Workflow & $1.447^{* *}$ & & 0.477 & 0.299 \\
\hline Utilization & 0.391 & & 0.447 & 0.085 \\
\hline Efficiency & $1.262 *$ & & 0.607 & 0.259 \\
\hline Strength & $1.309 * *$ & & 0.492 & 0.266 \\
\hline Constant & -2.098 & & 0.432 & \\
\hline $\mathrm{R}^{2}$ & & 0.683 & & \\
\hline F & & $51.258^{* *}$ & & \\
\hline
\end{tabular}

Note: $* *$ Correlation is significant at $p<0.01$ level

mean is of data accuracy which shows that most respondents believed that data accuracy is the real strength of system $(\mathrm{M}=4.03, \mathrm{SD}=0.69)$ (Figure 8).

Nurse's manager satisfaction: The findings reflected that $80.5 \%$ of the nurses' managers agreed that the workforce management system is effective in meeting their needs and expectation in managing staff. In addition a multiple linear regression analysis was performed to predict nurses' satisfaction level with the new Clairvia system based on the system's workflow, utilization, efficiency and strengths. Outliers were detected using Mahalanobis distance, cook's distance and leverage distance, cases which showed extreme value in two out of these three distance measures were marked as outliers and therefore eliminated from the analysis. The independent variables were log transformed to reduce the skewness and make them approximately normal. There were no issues of multicollinearity and auto-correlation and the residuals were approximately normally distributed. (Table 6, Figure 9).

Furthermore, the regression results found a significant regression equation $(\mathrm{F}(4,95)=51.258, \mathrm{p}<0.001)$ workforce system's workflow, utilization, efficiency and strengths explained $68.3 \%$ of variation

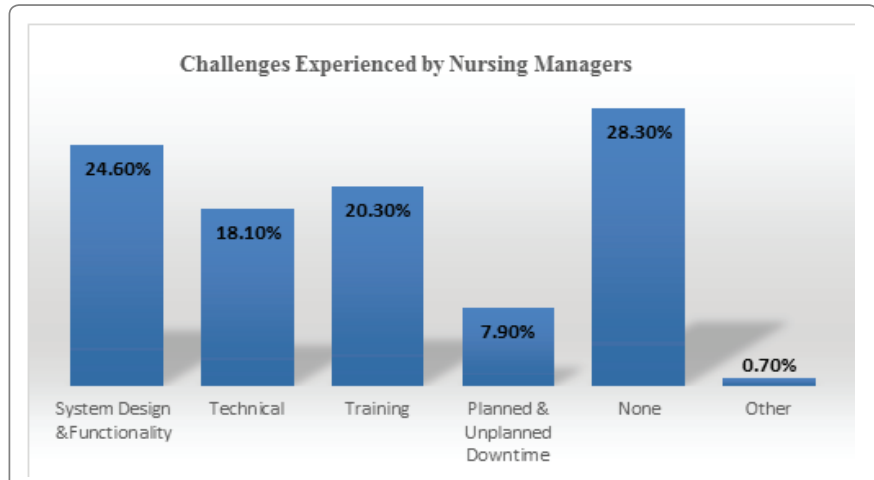

Figure 10: Challenges experienced by nurses managers.

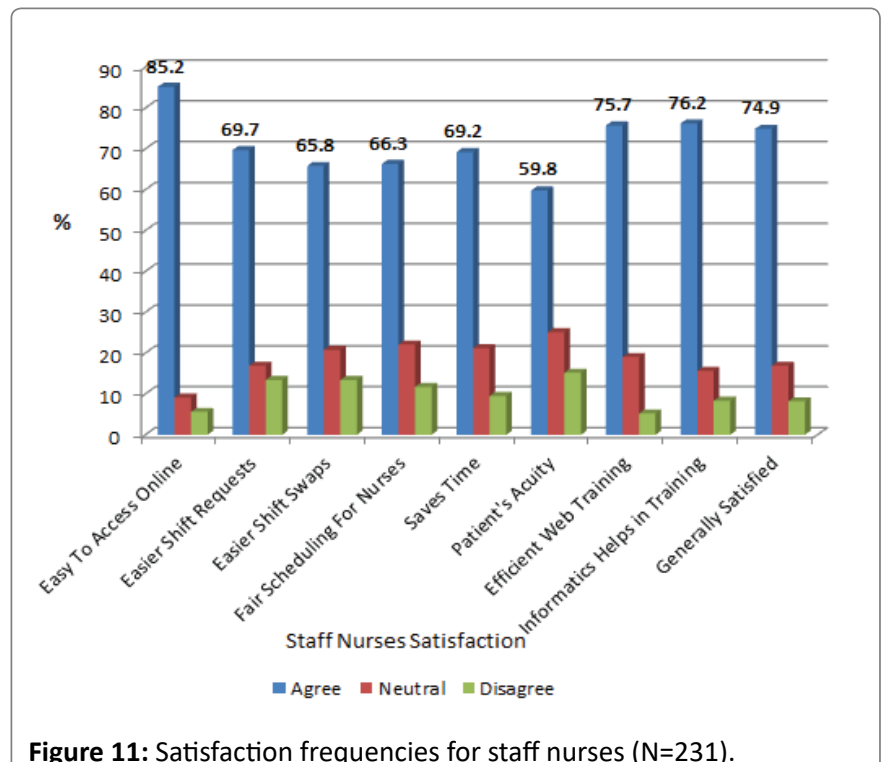

in nurse's satisfaction with system $\left(\mathrm{R}^{2}=0.683\right)$. Nurses' predicted satisfaction with the system is equal to $-2.098+1.447$ (Workflow) +1.262 (Efficiency)+1.309 (Strengths), where satisfaction, workflow, efficiency and utilization were measured on a 5-point Likert scale from 1(Strongly disagree) to 5(Strongly Agree). Nurses' satisfaction increased 1.447 units for each unit increase in the system's workflow $(B=1.447$, $\mathrm{SE}=0.477, \mathrm{p}<0.01)$. Nurses' satisfaction increased 1.262 units for each unit increase in system's efficiency $(B=1.262, S E=0.607, p<0.05)$. Nurses' satisfaction with Clairvia system increased 1.309 units for each unit increase in the system's strength $(\mathrm{B}=1.309, \mathrm{SE}=0.492, \mathrm{p}<0.01)$. On the other hand, Clairvia system's utilization was not a significant predictor of nurses' satisfaction with Clairvia system.

Factors affecting the utilization of the workforce management System: The findings revealed in figure 10 several difficulties experienced in the utilization of the system. the highest rate $28.3 \%$ there are no challenges the that system needs familiarization where $24.6 \%$ of the challenges reported were related to the system design and functionalities, followed by $20.3 \%$ due to training issues, $18.1 \%$ technical issues related to logging to system, slowness of the system while $7.9 \%$ of difficulties were related to system downtime whether planned or unplanned and the least challenges less than $1 \%$ were related to tickets and Request Of Change (RFC) requests processing workflow. 
Staff nurses' satisfaction (Survey 2): Overall the staff nurses agreed that they are satisfied with the new system implementation $(\mathrm{M}=3.74, \mathrm{SD}=0.75)$. They gave their answers regarding staff nurse's satisfaction. There were in total 9 questions to evaluate the satisfaction level. Pearson Correlation Analysis was performed to find out which variables correlate more significantly than other variables. The results indicate that the highest correlation was between question 2 (Making 'Shift Requests' is easier than previous paper based systems?) and question 3 (Making 'Shift Swaps' is easier than in previous paper based system?). There is a significant, positive and very strong correlation between Easier shift request and Easier Shift Swap $(\mathrm{r}(229)=0.875, \mathrm{p}<0.01)$. The second highest correlation was between Fair Scheduling for nurses and Saving Time $(r(229)=0.785$, $\mathrm{p}<0.01)$. Similarly, all the pairs have significant and moderate-tostrong correlation with each other. The weakest correlation was between question 1 (Making 'Shift Requests' is easier than previous paper based systems?) and question 6 (Clairvia system increased assignment fair distribution based on patient's acuity). The pair had significant but slightly moderate correlation $(\mathrm{r}(229)=0.483, \mathrm{p}<0.01)$ (Figure 11).

\section{Discussion}

Effective staffing management in clinical area is based on several dimensions, patient data, staff data and operations data in other words, unit dynamics such as admissions, discharge and transfers, patient acuity, patient care hours as per specialty and staff competency. The complexity of managing this data in Hamad Medical CorporationQatar raised the need of automating the process in order to optimize staffing and deliver best patient care with highest quality. Thus, the workforce management system was implemented to replace the Microsoft designed excel template for scheduling the staff and several paper forms for staff assignment, patient census and reports related to Admissions, Discharge and Transfers (ADT). In addition to legacy time management system integrated with the finance department system for managing staff attendance, absenteeism and overtime payments. The primary aim of implementing an integrated system was to have the ability to leverage nursing staff time, availability, experience, education and skills to meet patient care needs with consideration of unit turnover rate, and unexpected changes.

The impact of the system was measured based on five parameter, change in staffing management workflow, system utilization, effectiveness, strengths and staff satisfaction. The findings showed that the correlation between all the variables mean in nurses' manager survey had significant and positive correlations with each other. The strongest correlation is between efficiency and satisfaction $(\mathrm{r}(111)=0.811$, $\mathrm{p}<0.01)$. It shows that with the increase in efficiency of the system, the satisfaction of nurse's manager also increases significantly. Overall, $80.5 \%$ of nurses' managers agreed that the workforce management system is effective in managing staffing, in comparison between the previous staffing scheduling and current staffing management system. The majority of nursing managers agreed that the system has positively impacted their staffing workflow, in respect to $78 \%$, easier shift requests, $81 \%$ tasks done in timely manner, $78 \%$ efficient distribution of assignments, $84 \%$ provide accurate data and reports and $83 \%$ agreed that the system assisted them in efficient utilization of nursing resources. Moreover, the study revealed there is a significant, positive and very strong correlation between continuity of care feature and demand manager effectiveness $(r(111)=0.837, p<0.01)$. On the other hand, regardless of significant correlations and the positive impact of implementing the system there are existing challenges that affects the utilization of the system; the system functionalities and design include horizontal count so there will be fair number of shifts, determining the number of shifts per staff, and the printed duty roster all black and white, other related to technical issues as access from home is requested by end-users and slowness, training issues, request and shift swapping are not being utilized in the units because staffs are not comfortable to do it.

The results analysis of nurses' and nursing managers showed high level of agreement indicating that both agree that the workforce management system has significantly increased the efficiency and strengths of working and speeded up report generation for managers. It also allows fair and equitable distribution of work and allocation of shifts and patients. The results are in confirmation of previous studies conducted in this domain as it shows that digital management workflow systems are comparatively far more efficient than using spreadsheets or paper-based systems [10-12] has published a report based on data from more than 260 organizations in managing time and attendance stating that integration with payroll, scheduling and leave management emerges as a true driver of performance and have a positive impact on productivity, efficiency and compliance. Choi M, et al. [13] conducted systematic review. The study finding showed that nurses were satisfied with using nursing workforce management system, as effective and useful system in saving time and reducing cost.

One of the significant impact of the implementation the ability to assign the staff according to patients acuity and ensuring the continuity of care, which enabled the nursing managers to assign nurses to be allocated to familiar patients which eased the pressure of work. The workforce system also assisted in easiness of scheduling, accuracy of data and rapid report generation. On the other hand, workforce system's utilization was not significant in increasing satisfaction of managers. It appears that managers might need some significant improvement in scheduling functionalities especially with system designs and the ability to project and plan for future schedules. The results of this study related to the efficiency, strengths and workflow are in agreement with previous studies on workforce management systems.

In conclusion, automating staffing management has positive impact on the nurses' manager and staff nurses but the more the integrated the system with assignments the higher the satisfaction and the highest the need for continuous training and familiarization with it in addition to system monitoring and optimization. Overall, both managers and the nurses are highly satisfied with the implementation of the new workforce management systems as it increased the efficiency of work and enhanced the workflow, but the managers expect further improvement in the quality of data and scheduling functionalities of the system.

\section{Conclusions}

Despite of the system positive impact on staffing management practice and highest rate of satisfaction reported by both nursing managers and staff nurses. The system has some functionalities to enhance its utilization of staff, fair distribution of assignments and clear communication between the managers and staff needs enhancement. In addition to further studies to cover the relation between patient acuity and demand manager, best practices for setting staffing shift pattern and its relation to staff satisfaction and examining the relation of automating staffing and its impact on workforce budget planning for the nursing department in HMC. Nurses who belonged to women's hospital were generally less satisfied with the new system compared to the nurses of all 
other hospital facilities. They should be further investigated about what caused a certain level of dissatisfaction and what changes they might want to see in the system to increase their satisfaction. The developers of the new workforce system should also be advised to keep a prior focus on effective communication mechanism of the system so that it makes two-way communication of messages regarding shifts and reports between managers and nurses as smooth and as efficient as possible.

\section{References}

1. Gavigan M, Fitzpatrick TA, Miserendino C (2016) Effective Staffing Takes a Village: Creating the Staffing Ecosystem. Nurs Econ 34: 5865.

2. Douglas KS (2016) Why We Should be Paying Attention to the Evolving World of Staffing Technology Solutions. Nurs Econ 34: 255256.

3. Crist-Grundman D, Mulrooney G (2011) Effective workforce management starts with leveraging technology, while staffing optimization requires true collaboration. Nurs Econ 29: 195-200.

4. Bowie D (2018) 6 strategies for successful workforce technology implementation Use data-driven workforce management to improve hospital staffing and scheduling. Am Nurse Today 9-12.
5. Hustad NB, Helles $\varnothing$ R, Andersen MH (2015) A Qualitative Study of Manager Experiences Using the RAFAELA System. Open J Nurs 5: 1024-1032.

6. Myny D, Van Goubergen D, Gobert M, Vanderwee K, Van Hecke A, et al (2011) Non-direct patient care factors influencing nursing workload: a review of the literature. J Adv Nurs 67: 2109-2129.

7. Concerro (2009) Open shifts filled nationally. Annual report to client organization. San Diego.

8. Haley S, Thering D (2009) Mild-Michigan: Nursing/Finance Collaboration-More than Just staffing, a vehicle for controlled change.

9. Foster R (2013) New Zealand DHB Nurse Roster Systems.

10. Aberdeen Group: A Harte-Hanks Company (2011).

11. Ivory CH (2015) The role of health care technology in support of perinatal nurse staffing. J Obstet Gynecol Neonatal Nurs 44: 309316.

12. Raethel K, Concerro (2009) Improves workforce Management for Castle Medical Center.

13. Choi M, Yang YL, Lee SM (2014) Effectiveness of nursing management information systems: a systematic review. Healthc Inform Res 20: 249-257. 